\title{
FINE NEEDLE ASPIRATION CYTOLOGY AS A DIAGNOSTIC MODALITY IN LYMPH NODE SWELLING IN RURAL INDIA
}

\author{
CHAKRABORTY. A ${ }^{1}$, REANG. J. $P^{2}$, YASUNG. $P^{3} \&$ NATH. $\mathrm{S}^{4}$
}

${ }^{I}$ Post Graduate Student, Department of Pathology, Tripura Medical College and Dr. BRAM Teaching Hospital, Hapania, Agartala, Tripura, India

${ }^{2}$ Assistant Professor, Department of Pathology, Tripura Medical College and Dr. BRAM Teaching Hospital, Hapania, Agartala, Tripura, India

${ }^{3}$ Senior Resident, Department of Pathology, Tripura Medical College and

Dr. BRAM Teaching Hospital, Hapania, Agartala, Tripura, India

${ }^{4}$ Professor \& Head of Department, Department of Pathology, Tripura Medical College and

Dr. BRAM Teaching Hospital, Hapania, Agartala, Tripura, India

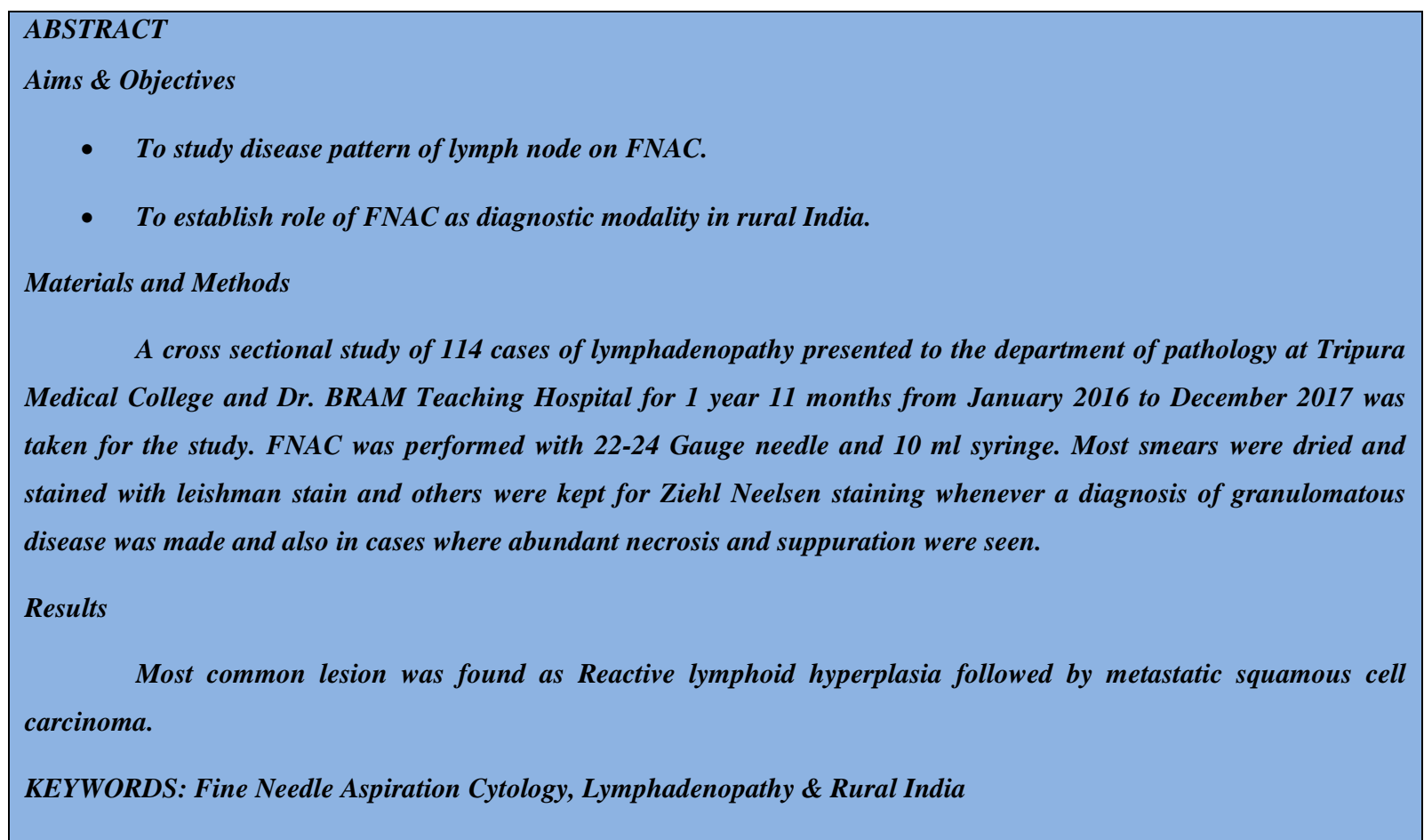

Received: Dec 31, 2018; Accepted: Jan 21, 2019; Published: Feb 14, 2019; Paper Id.: IJBTRJUN20193

\section{INTRODUCTION}

Lymphadenopathy is one of the commonest clinical presentations in out-patient departments. The degree and pattern of morphological changes depend on inciting stimulus and intensity of response. ${ }^{[1]}$ FNAC is an immediate, preliminary although not always specific diagnosis with little trauma and cost, which informs and leads the pathway to further management.

The etiology of lymphadenopathy varies from an inflammatory process to malignant lesion. The knowledge of the pattern of lymphadenopathy in a given geographical region is essential for making a 
confident diagnosis or suspecting a disease. FNAC has been used extensively in the diagnosis of primary and secondary lymphadenopathy. ${ }^{[1]}$

The present study was undertaken to determine the role of FNAC in the evaluation of cytomorphological features of various lymph node lesions.

Our experience of the diagnostic utility of FNAC in the assessment of lymphadenopathy is presented.

\section{MATERIALS AND METHODS}

A prospective study of 114 cases of lymphadenopathy presenting to the Department of Pathology for 2 years from January 2016 to December 2017 was taken up for the study. FNAC was performed with 22-24 gauge needle and $10 \mathrm{ml}$ syringe. Most of the smears were stained with leishman stain and some were kept unstained for performing Ziehl-Neelsen stain wherever a cytological diagnosis of granulomatous disease was made and in cases with abundant necrosis and suppuration. In cases where fluid was aspirated, the fluid was centrifuged and smears were made from the sediment, followed by the above staining method.

\section{RESULTS}

Among 515 cases obtained in Cytopathology section in 1 year 11 month period 114 were FNAC of a lymph node. Most common lesion found were Reactive lymphoid hyperplasia in 42 cases.(36.8\%) followed by 33 cases of Metastatic tumours (28.9\%), granulomatous lymphadenitis in 22 cases(19.2\%),10 cases of Non-Hodgkin lymphoma(8.7\%), 3 cases of Hodgkin lymphoma(2.6\%) and 4 cases of acute suppurative lesion (3.5\%). Age of the patients ranged from 8 years to 80 years. Age and sex distribution of patients are given in Table no. 2 and Table no. 3. The youngest patient was diagnosed as Reactive lymphoid hyperplasia and the eldest patient was diagnosed as having a metastatic deposit in lymph node. Metastatic deposits and Non-Hodgkin lymphomas are more common in elderly patients. Total no. Of male patients were 64 and total no. of the female patients were 50. Male: Female ratio is 1.28:1. All the entities are more common in males.

Table 1: Distribution of Fine Needle Aspiration Cytology Diagnosis of 114 Cases

\begin{tabular}{|l|c|c|}
\hline \multicolumn{1}{|c|}{ Cytological Diagnosis } & No. of Cases & Percentage \\
\hline Reactive lymphoid hyperplasia & $\mathbf{4 2}$ & $\mathbf{3 6 . 8 \%}$ \\
\hline Metastatic tumours & $\mathbf{3 3}$ & $\mathbf{2 8 . 9 \%}$ \\
\hline Granulomatous lymphadenitis & $\mathbf{2 2}$ & $\mathbf{1 9 . 2 \%}$ \\
\hline Non-Hodgkin Lymphoma & $\mathbf{1 0}$ & $\mathbf{8 . 7 \%}$ \\
\hline Hodgkin lymphoma & $\mathbf{0 3}$ & $\mathbf{2 . 6 \%}$ \\
\hline Acute suppurative lesion & $\mathbf{0 4}$ & $\mathbf{3 . 5 \%}$ \\
\hline
\end{tabular}

Table 2: Age Distribution of Patients

\begin{tabular}{|c|c|c|c|c|c|c|}
\hline Age & Reactive & Metastatic & Granulomatous & NonHodgkin & Hodgkin & Acute Suppurative \\
\hline $0-10$ years & 10 & Nil & 02 & Nil & 01 & Nil \\
\hline $11-20$ & 09 & Nil & 03 & Nil & 02 & 01 \\
\hline $21-30$ & 10 & 01 & 08 & Nil & Nil & 02 \\
\hline $31-40$ & 10 & 02 & 02 & Nil & Nil & Nil \\
\hline $41-50$ & 03 & 06 & 01 & Nil & Nil & 01 \\
\hline $51-60$ & Nil & 10 & 02 & 06 & Nil & Nil \\
\hline $61-70$ & Nil & 08 & 02 & 02 & Nil & Nil \\
\hline $71-80$ & Nil & 06 & 02 & 02 & Nil & Nil \\
\hline $81-90$ & Nil & Nil & Nil & Nil & Nil & Nil \\
\hline
\end{tabular}


Table 3: Sex Distribution of Patient

\begin{tabular}{|c|c|c|c|c|c|c|}
\hline Gender & Reactive & Granulomatous & Metastatic & Non Hodgkin & Hodgkin & Acute Suppurative \\
\hline Male & $\mathbf{2 7}$ & 12 & 25 & 06 & 03 & 02 \\
\hline Female & $\mathbf{1 5}$ & 10 & 08 & 04 & 00 & 02 \\
\hline
\end{tabular}

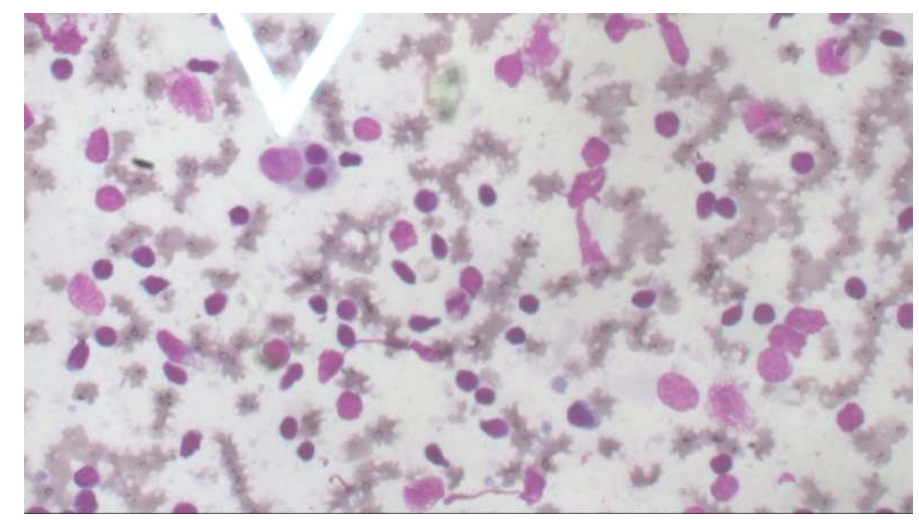

Figure 1: Reactive Lymph Node Showing Tangible Body Macrophages. Leishman Stain

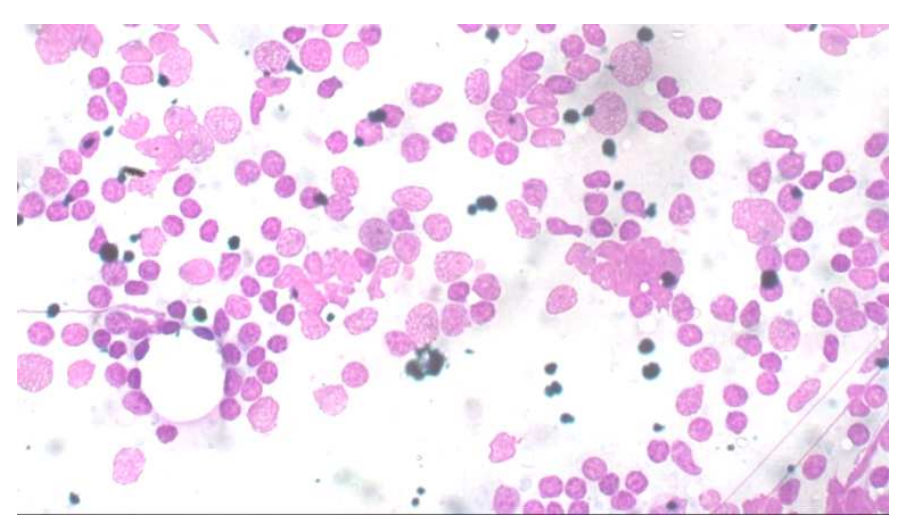

Figure 2: Hodgkin's Lymphoma Showing Classic Hodgkin's Cells and Reed Sternberg Cells

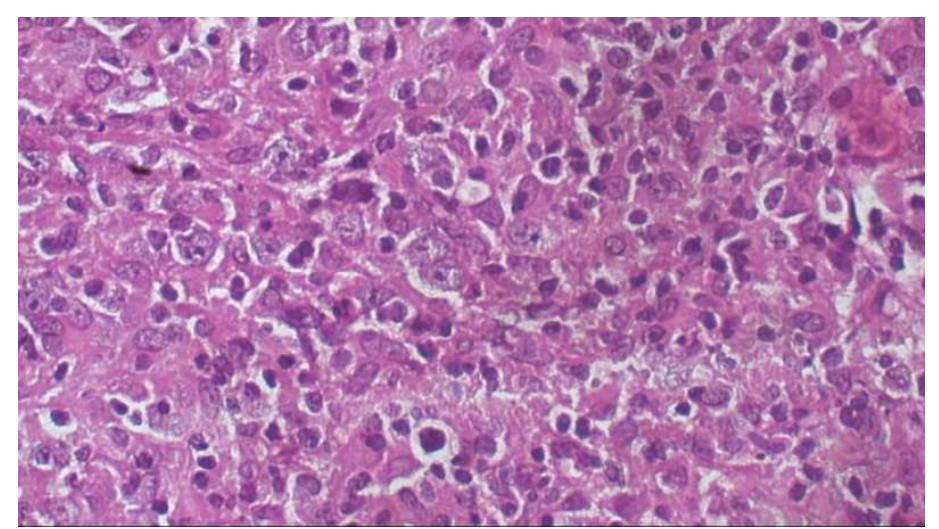

Figure 3: Histopathological Picture Showing Hodgkin Lymphoma. H \& E Stain 


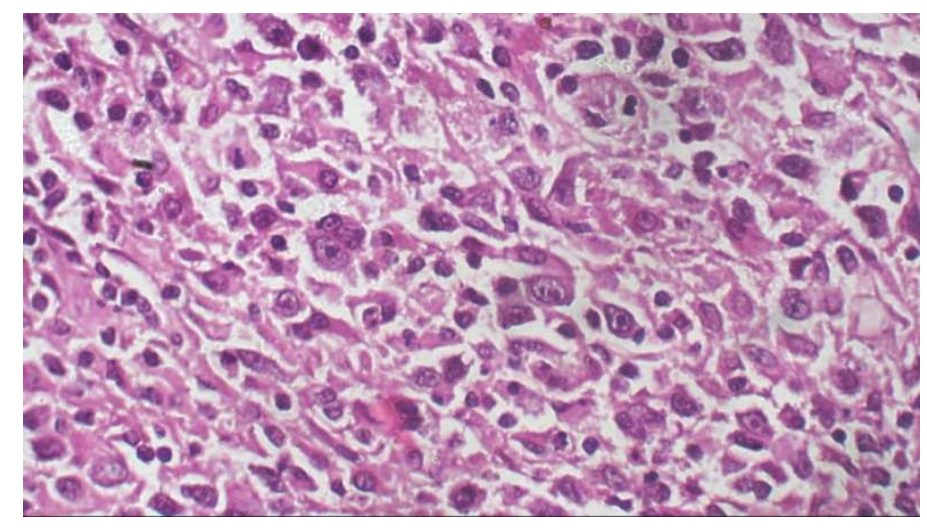

Figure 4: Hodgkin Lymphoma

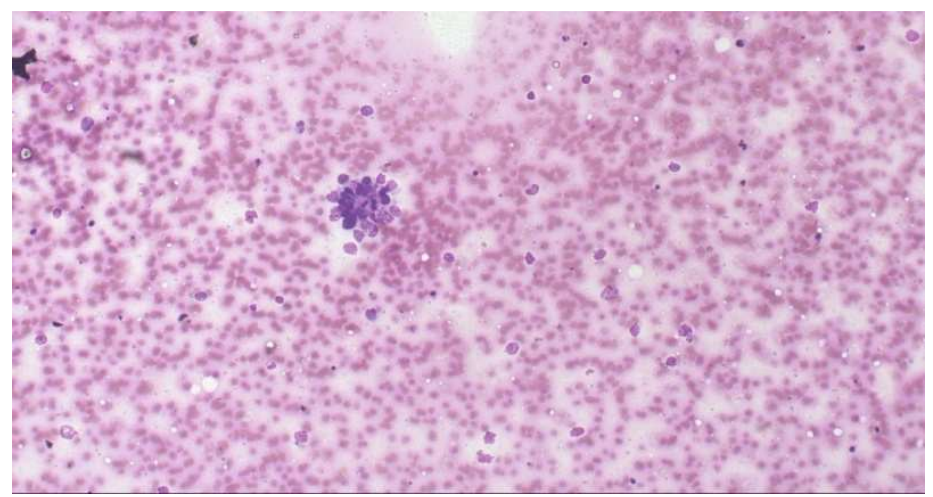

Figure 5: Metastatic Adenocarcinoma Showing Cells Arranged in Glandular Pattern

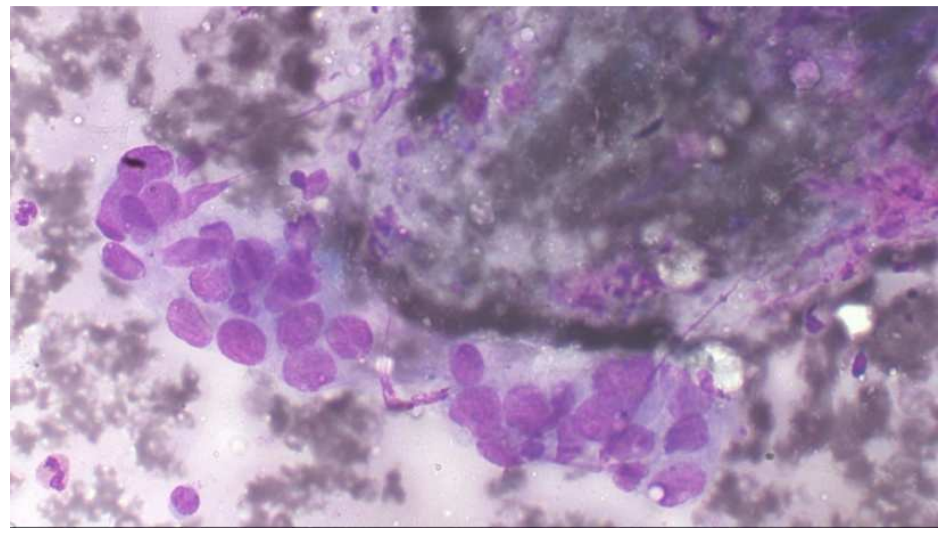

Figure 6: Metastatic Squamous Cell Carcinoma Showing Cells with Glassy Cytoplasm 


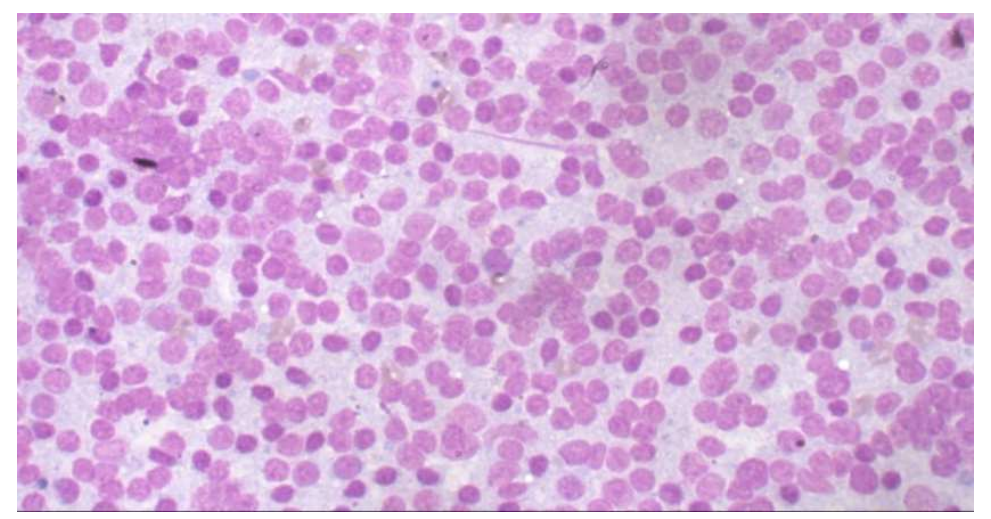

Figure 7: Non Hodgkin Lymphoma

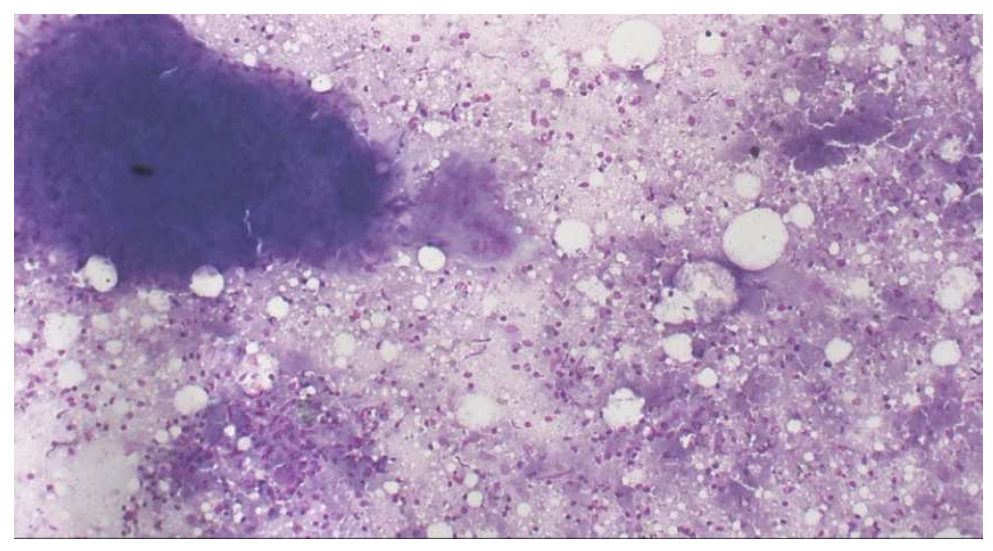

Figure 8: Necrotizing Granuloma

\section{DISCUSSIONS}

FNAC is a simple, safe, cost-effective, quick as well as an efficient diagnostic procedure with relatively no contraindications and no side-effects. It forms an important tool for diagnosing various causes of lymphadenopathy. ${ }^{[2,4,5]}$

In our study, there was a male preponderance with male: female ratio 1.7:1. This is in accordance with various other studies with similar findings. ${ }^{[1,2,3,7,10]}$

Lymph node enlargement can occur in a diverse age group from a very early age to elderly. ${ }^{[2]}$ In our study youngest patient was 3 years old and eldest patient was 80 years old.

The causes of lymphadenopathy were diverse, ranging from innocuous reactive hyperplasia, suppurative pathologies and granulomatous lesions to dreaded malignancies, i.e, lymphomas and metastatic carcinomas. Out of a total of 114 cases 42 cases (36.8\%) were patient of Reactive lymphoid hyperplasia. That is the majority of cases presented with reactive lymphoid hyperplasia, which correlates with the study of Manas Madan et $\mathrm{al}^{[2]}$ and various other studies.

Malignant pathology accounted for $28.9 \%$ of cases. These were mostly cases of Metastatic squamous cell carcinoma, Adenocarcinoma, Non-Hodgkin lymphoma and Hodgkin lymphoma. The highest incidence of malignancy was seen in $5^{\text {th }}$ decade, which correlates with the study of Dr. Haricharan Perigela ${ }^{[3]}$ in a tertiary hospital in Kurnool.

Granulomatous pathology accounted for $19.2 \%$ of cases which again correlated with Study by Manas Madan et al. ${ }^{[2]}$ 


\section{CONCLUSIONS}

FNAC of lymph nodes proved to be a very useful tool in the diagnosis early diagnosis and evaluation of enlarged lymph nodes. It is useful in the diagnosis of both neoplastic and non-neoplastic lesions with good sensitivity and specificity. In many cases it reduces the need for a surgical procedure to be performed. Our study highlighted the various cytomorphological patterns of lymphadenopathy and revealed the predominance of Reactive lymphoid hyperplasia among all the causes of Lymphadenopathy.

\section{REFERENCES}

1. Badge S A, Ovhal A G,Azad K, Meshram T.A. Study of Fine-nedle Aspiration cytology of lymph node in rural area of Bastar district,chattisgarh.;J Dr.DY Patil Vidyapeeth 2017, 10:143-146.

2. Madan M,Kaur P, Manjari M,Sharma M; FNAC as a diagnostic tool in the evaluation of Lymphadenopathy -A tertiary Care Hospital Experience.2014; vol.14,Issue 7 version 1.0

3. Dr Haricharan Perigela A study of FNAC of cervical lymph nodes in Tertiary hospital 2015; vol 5, Issue 10.

4. Hirachand S, Lakhey M,Akhter J,Thapa B.a Evaluation of fine needle aspiration cytology of lymph nodes in Kathmandu Medical College and Teaching Hospital;Kathmandu university Medical journal.2007;7:139-42.

5. Malakar D, Jajoo ILN, Swarup K, Gupta O P, Jain AP, Poflee VW Aclinical evaluation of Fine needle Aspiration Cytology in the Diagnosis of Lymphadenopathy.Ind J Tub.1991;38:17-19.

6. Kataria P, Sachdeva M, Singh NK. FNAC as a diagnostic tool for the diagnosis of cervical lymphadenopathy. Bull.Environ.Pharmacol.Life Sci.2012;1(8):72-75.

7. Shakya G, Malla S, Shakya KN, Shreshtha R A study of FNAC of cervical lymph nodes;JNHRC;2009; Vol 7,No.1

8. Pandit AA, Candes FP, Khubchandani SR.Fine needle aspiration cytology of lymph node J postgrad Med 1987;33:134-136.

9. N Gurabani Study of FNAC of Head and Neck Region in Chattisgarh population of Both Sexes 2018;4:27-29.

10. Khattar N, Dorairajan L.N., and K. Santosh Role of simultaneous fine needle aspiration cytology of palpable inguinal lymph node and Primary tumour biopsy in carcinoma of the penis.Indian J Urol.2007 Apr-Jun;23(2):220-221. 